\title{
Gangguan Monyet Ekor Panjang (Macaca fascicularis) Sekitar Pemukiman di Desa Tumuk Manggis dan Desa Tanjung Mekar, Kecamatan Sambas, Kalimantan Barat
}

\author{
Ozy Oriza $^{1}$, Tri Rima Setyawati ${ }^{1}$, Riyandi ${ }^{1}$ \\ ${ }^{1}$ ProgramStudiBiologi, FakultasMIPA, Universitas Tanjungpura, Jl. Prof. Dr. H. HadariNawawi, Pontianak \\ Email: ozy.oriza@gmail.com
}

\begin{abstract}
Long-tailed macaque (Macaca fascicularis) is one of the primates that can coexist with humans, but the use of land into human settlements can lead to reduced habitat for long-tailed monkeys and cause monkeys to disturb humans. This study was conducted to determine the disturbances of long-tailed macaque (Macaca fascicularis)in Tumuk Manggis and Tanjung Mekar Villages, Sambas District, West Borneo. This study used in-depth interviews method to collection data of disturbance. Data collected were analyzed quantitative descriptively. The results showed that the disturbances carried out by long-tailed macaque when entering the residential area are to steal fruit or food at the people's plantations or the backyard of people's homes. The forest in the study area does not provide abundant feed and the land that is converted into a building allows long-tailed monkeys to enter residential areas.
\end{abstract}

Keyword :Long-tailed macaque (Macaca fascicularis), disturbance, residence area

\section{PENDAHULUAN}

Pemanfaatan lahan oleh manusia perlu berdasarkan pada prinsip ekoefisiensi, artinya tidak merusak ekosistem, pengambilan secara efisien dalam memikirkan kelanjutan sumber daya manusia (Soerianegara, 1997). Pemanfaatan lahan di Desa Tumuk Manggis dan Desa Tanjung Mekar, Kecamatan Sambas, semakin meningkat dengan bertambahnya penduduk, seperti pembangunan tempat tinggal dan kebunyang mendorong terjadinya pembukaan lahan.

Penggunaan lahan yang tidak terkendali akan mengganggu habitat satwa yang ada di kawasan tersebut. Desa Tumuk Manggis dan Tanjung Mekar merupakan salah satu habitat monyet ekor panjang karena desa tersebut memiliki hutan dan berada di tepian sungai tempat yang sesuai bagi monyet ekor panjang. Monyet ekor panjang termasuk jenis hewan yang mudah beradaptasi dengan lingkungannya, sehingga spesies ini dapat ditemukan pada berbagai tipe habitat mulai dari hutan alam maupun hutan sekunder.

Berkurangnya habitat menyebabkan perubahan perilaku harian monyet ekor panjang. Berkurangnya lahan akan mengganggu keberadaan habitat monyet sehingga dapat mengganggu masyarakat, merusak tanaman, hewan ternak dan perkebunan warga.
Perubahan habitat akan menarik populasi monyet ekor panjang untuk menggunakan areal sekitar pemukiman atau ladang sebagai habitatnya. Penelitian ini dilakukan untuk mengetahui gangguan yang disebabkan oleh monyet ekor panjang di Desa Tumuk Manggis dan Tanjung Mekar.

\section{BAHAN DAN METODE}

\section{Waktu dan Tempat Penelitian}

Penelitian ini dilaksanakan di areal hutan sekitar pemukiman Desa Tumuk Manggis dan Desa Tanjung Mekar Kecamatan Sambas, Kabupaten Sambas, selama dua bulan yaitu November Desember 2017.

\section{Deskripsi Lokasi}

Lokasi penelitian berada di dua desa yaitu Desa Tumuk Manggis dan Desa Tanjung Mekar, Kecamatan Sambas, Kalimantan Barat. Daerah Desa Tanjung Mekar memiliki luas area sebesar 360 Ha dengan topografi dataran rendah, masih banyak terdapat lahan kosong seluas 185,96 Ha disekitarnya yang banyak ditumbuhi pohon-pohon akasia, dan berada di pinggiran sungai. Desa Tanjung Mekar berbatasan dengan Desa Tumuk Manggis yang memiliki luasan $89 \mathrm{Ha}$ dengan 


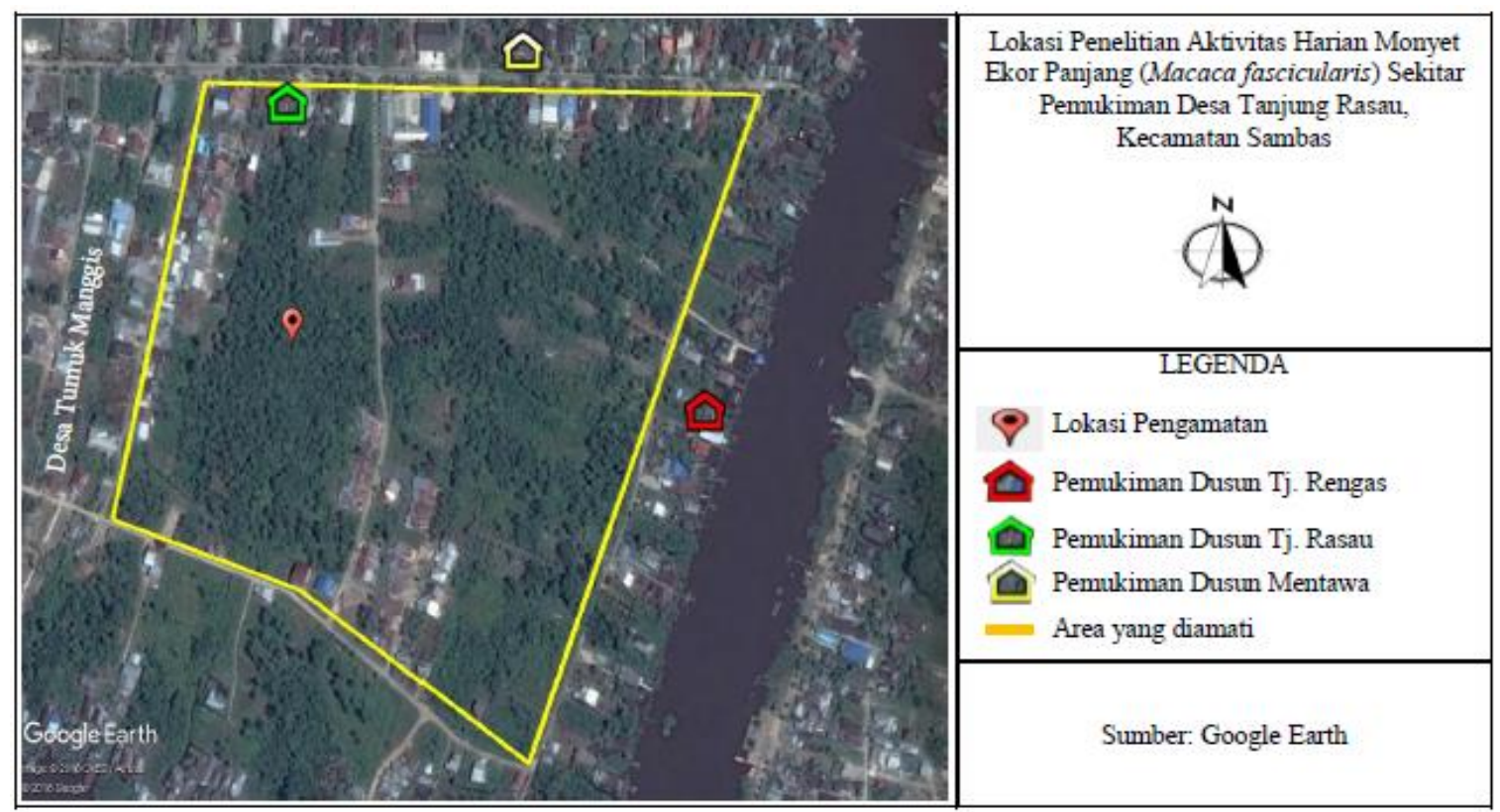

Gambar 1. Peta Lokasi Penelitian

topografi dataran redah, berada di pinggiran sungai dan padat penduduk (BPD, 2016).

\section{Alat dan Obyek}

Alat-alat yang digunakan dalam penelitian ini adalah alat tulis, binokuler dan obyek yang diamati adalah monyet ekor panjang (Macaca fascicularis).

\section{Prosedur Kerja}

\section{Gangguan Monyet Ekor Panjang}

Pengambilan data gangguan monyet ekor panjang dilakukan melalui wawancara mendalam terhadap 20 orang warga setempat yang berada di sekitar lokasi penelitian untuk mengetahui gangguan yang dilakukan oleh monyet ekor panjang di area pemukiman penduduk

\section{Analisis Data}

Data dari hasil wawancara dianalisis deskriptif dengan mempersentasikan gangguan yang dilakukan oleh monyet ekor panjang.

\section{HASIL DAN PEMBAHASAN}

\section{Hasil}

Wawancara terhadap 20 responden yang tinggal di sekitar lokasi penelitian, 55\% responden diantaranya menyebutkan bahwa monyet ekor panjang sering memasuki wilayah pemukiman pada waktu siang menjelang sore hari tepatnya pukul 14.00-18.00, sedangkan 30\% lainnya menyebutkan monyet ekor panjang memasuki wilayah pemukiman pada waktu pagi hari (07.00-11.00), sebanyak $15 \%$ responden menyebutkan monyet ekor panjang memasuki wilayah pemukiman pada waktu pagi dan siang hari(Tabel 1).

Tabel 1. Waktu monyet ekor panjang masuk pemukiman

\begin{tabular}{cc}
\hline Waktu & Responden $(\%)(\mathrm{n}=20)$ \\
\hline $07.00-11.00$ & 30 \\
$14.00-18.00$ & 55 \\
Keduanya & 15 \\
\hline
\end{tabular}

Menurut $85 \%$ responden yang diwawancarai, jumlah monyet ekor panjang yang memasuki pemukiman berkisar 1-10 ekor dan 15\% responden lainnya menyebutkan sebanyak 11-20 ekor (Tabel 2).

Tabel 2. Jumlah monyet ekor panjang saat memasuki pemukiman

\begin{tabular}{cc}
\hline Jumlah(ind) & Responden $(\%)(\mathrm{n}=20)$ \\
\hline $1-10$ & 85 \\
$11-20$ & 15 \\
$>20$ & 0 \\
\hline
\end{tabular}

Berdasarkan umur monyet ekor panjang yang memasuki wilayah pemukiman, $75 \%$ responden menyebutkan monyet dewasa dan $25 \%$ responden menyebutkan monyet remaja, sedangkan anakan tidak pernah terlihat memasuki wilayah pemukiman (Tabel 3). 
Tabel 3. Tingkat umur monyet ekor panjang yang memasuki pemukiman

\begin{tabular}{cc}
\hline Tingkat Umur & Responden $(\%)(\mathrm{n}=20)$ \\
\hline Dewasa & 75 \\
Remaja & 25 \\
Anakan & 0 \\
\hline
\end{tabular}

Berdasarkan informasi yang didapat, apabila monyet ekor panjang memasuki wilayah pemukiman, $60 \%$ responden menyebutkan sering bertengger di pohon dekat rumah warga, 15\% responden menyebutkan di pagar dan 25\% responden menyebutkan pernah berada di atap rumah (Tabel 4).

Tabel 4. Lokasi monyet ekor panjang pada saat memasuki pemukiman

\begin{tabular}{cc}
\hline Lokasi & $\begin{array}{c}\text { Responden } \\
(\%)(\mathrm{n}=20)\end{array}$ \\
\hline Atap rumah & 25 \\
Teras rumah & 0 \\
Pohon dekat rumah & 60 \\
Pagar rumah & 15 \\
\hline
\end{tabular}

Sebanyak $65 \%$ responden menyebutkan bahwa, monyet ekor panjang pada saat melihat manusia langsung pergi, beberapa responden menyebutkan ada monyet bergerombolan pada saat melihat manusia monyet tersebut hanya diam dan tidak mau pergi dan juga menjadi agresif (Tabel 5.)

Tabel 5. Respon monyet ekor panjang pada saat melihat manusia

\begin{tabular}{cc}
\hline Aktivitas & Responden $(\%)(\mathrm{n}=20)$ \\
\hline Hanya diam & 20 \\
Langsung pergi & 65 \\
Menyerang & 5 \\
Agresif & 10 \\
\hline
\end{tabular}

Responden yang menyatakan bahwa monyet ekor panjang tidak pernah menggangu manusia ataupun menggigit manusia yaitu sebanyak $85 \%$, akan tetapi $15 \%$ responden yang diwawancarai pernah terganggu dengan keberadaan monyet ekor panjang. Sebanyak $10 \%$ responden memiliki rasa takut terhadap monyet ekor panjang. Terdapat 25\% responden menyatakan bahwa pernah melihat orang lain dikejar dan diganggu oleh monyet ekor panjang (Tabel 6.).

Aspek-aspek negatif keberadaan monyet ekor panjang di daerah pemukiman Desa Tumuk Manggis dan Tanjung Mekar, tidak dihiraukan oleh masyarakat sekitar. Tetapi terdapat $35 \%$ responden yang menyatakan bahwa kehadiran monyet ekor panjang menggangu dan memengaruhi keselamatan dan kesehatan warga, terutama bagi anak-anak dan bayi. Beberapa responden yang memiliki kebun menyatakan bahwa monyet ekor panjang juga sering mencuri buah dan hasil panen bahkan menyerang hewan peliharaan. Terdapat $15 \%$ responden yang menyatakan bahwa monyet ekor panjang pernah memasuki dapur atau halaman belakang rumah dan $40 \%$ respoden menyebutkan monyet ekor panjang pernah mencuri makanan dan buah (Tabel 7).

Tabel 6. Responden yang takut, terganggu dan digigit monyet ekor panjang

\begin{tabular}{cc}
\hline Kategori & Responden $(\%)(\mathrm{n}=20)$ \\
\hline Takut & 10 \\
Diganggu & 15 \\
Melihat orang lain & 25 \\
diganggu & \\
Telah digigit & 0 \\
\hline
\end{tabular}

Tabel 7. Pandangan responden tentang konsekuensi dari kehadiran monyet ekor panjang

\begin{tabular}{lc}
\hline \multicolumn{1}{c}{ Konsekuensi } & $\begin{array}{c}\text { Responden } \\
(\%)(\mathrm{n}=20)\end{array}$ \\
\hline Memengaruhi & 35 \\
Keselamatan dan & \\
kesehatan warga & \\
Memasuki rumah & 15 \\
Pencurian & 40 \\
$\quad$ - Makanan & 15 \\
- Minuman & - \\
$-\quad$ Buah-buahan & 25 \\
\hline
\end{tabular}

Menurut $75 \%$ responden, usaha untuk mengurangi gangguan monyet ekor panjang telah dilakukan oleh warga seperti membangun pagar dan 25\% responden hanya melakukan pengusiran. Terdapat 75\% responden menyarankan agar pemerintah mengikutsertakan dalam mengurangi gangguan monyet ekor panjang yaitu $60 \%$ responden menyarankan untuk memindahkan monyet ekor panjang ke kebun binatang dan $15 \%$ respondenmenyarankan untuk membuat tempat pemeliharaan di lokasi penelitian. Akan tetapi terdapat $25 \%$ responden menyatakan bahwa tidak perlunya keikutsertaan pemerintah dalam 
menanggulangi gangguan monyet ekor panjang karena gangguan tersebut tidak banyak (Tabel 8).

Tabel 8. Tindakan dan saran warga kepada pemerintah untuk mengurangi gangguan monyet ekor panjang

\begin{tabular}{lc}
\hline \multicolumn{1}{c}{ Tindakan } & $\begin{array}{c}\text { Responden } \\
(\%)(\mathrm{n}=20)\end{array}$ \\
\hline Membangun pagar & 75 \\
Hanya mengusir & 25 \\
Tanpa peran pemerintah & 25 \\
Peran pemerintah & 75 \\
$\quad$ - Memindahkan & 60 \\
$\quad$ ke kebun & \\
$\quad$ binatang & \\
Membuat tempat & 15 \\
\hline
\end{tabular}

\section{Pembahasan}

Berdasarkan informasi warga, monyet ekor panjang sering memasuki area pemukiman pada pukul 14.00-18.00, karena pada waktu tersebut merupakan periode aktif monyet ekor panjang untuk melakukan aktivitas moving, menjelajah dan mencari makan. Monyet dewasa sering memasuki area pemukiman dengan jumlah yang tidak menentu. Saraswat et al. (2015) menyatakan bahwa, monyet jantan alpha akan pertamakali masuk ke area pemukiman, apabila tidak ada ancaman jantan alpha akan melakukan vocaluntuk memanggil monyet dewasa lainnya.

Menurut Hambali et al. (2012), monyet ekor panjang memasuki area manusia dikarenakan tingkat penasaran yang tinggi dan adanya dorongan untuk mencari makanan baru yang dimiliki oleh manusia.Ganguly dan Pradipika (2018) menyatakan bahwa, monyet memasuki area manusia untuk mengabil makanan dikarenakan monyet membutuhkan nutrisi untuk melakukan aktivitasnya dan bertahan hidup. Serangan monyet biasanya terjadi pada siang hari dan menjelang sore, karena pada waktu tersebut banyak makanan bekas manusia dan beberapa alasan karena tingkat penasaran untuk mengunjungi kembali tempat yang telah dijumpai oleh monyet ekor panjang pada saat pagi hari. Mendis dan Ashoka (2016) menyatakan bahwa, monyet akan terus kembali dan tetap berada disekitar area yang mudah ditemukannya makanan manusia.

Berdasarkan informasi warga, pada saat monyet memasuki area pemukiman monyet ekor panjang paling sering berada di pohon dekat rumah, akan tetapi ada beberapa responden yang menyatakan bahwa, monyet ekor panjang menaiki atap rumah. Menurut Lane et al. (2010), monyet ekor panjang yang memasuki kawasan pemukiman akan memilih tempat yang strategis agar lebih mudah menghindar dan mengawasi kehadiran manusia. Monyet ekor panjang akan mengawasi kehadiran manusia terlebih dahulu dari kejauhan atau dari pohon yang berada di dekat pemukiman sebelum memasuki wilayah tersebut dan mengambil sesuatu yang diinginkannya (Kumar, 2014).

Menurut responden, monyet ekor panjang pada saat melihat manusia akan langsung pergi dan apabila berkelompok monyet ekor panjang tesebut tidak lari tapi menjadi agresif dengan mengeluarkan suara menggeram. Menurut Hambali et al. (2012), monyet ekor panjang yang bergerombolan pada saat melihat manusia akan menjadi agresif dan akan menyerang manusia karena merasa terancam ataupun terganggu.

Berdasarkan informasi yang didapat, gangguan yang paling sering dilakukan monyet ekor panjang yaitu memasuki perkebunan warga dan mencuri buah atau hasil panen warga. Terdapat beberapa kasus monyet ekor panjang saat memasuki halaman belakang rumah warga, monyet-monyet tersebut mencuri makanan dan mengganggu ternak. Hutan di lokasi penelitian tidak menyediakan pakan yang melimpah dan lahan yang diubah fungsi menjadi bangunan sehingga memungkinkan monyet ekor panjang masuk ke wilayah pemukiman.

Widiyanti (2001) menyatakan bahwa, monyet ekor panjang akan memasuki lahan dan area pemukiman dikarenakan pakan di hutan sedikit, sehingga akan pergi untuk mencari makanan di wilayah manusia. Akan tetapi pada saat ini gangguan tersebut berkurang karena adanya perburuan sehingga gangguan monyet ekor panjang semakin berkurang.Menurut Dipak dan Sudipta (2015), konflik antara manusia dan monyet ekor panjang akan menyebabkan pemburuan terhadap monyet ekor panjang tersebut berkurangnya populasi monyet ekor panjang dan manusia dapat dianggap sebagai predator bagi monyet ekor panjang. Akibat perburuan tersebut monyet ekor panjang meningkatkan kewaspadaannya terhadap manusia untuk menghindari berkurangnya populasi (Hambali et al., 2012).

Warga di lokasi penelitian telah melakukan tindakan untuk mengurangi gangguan monyet ekor 
panjang seperti membangun pagar ataupun hanya sekedar mengusir untuk memberikan efek jera terhadap monyet ekor panjang sehingga tidak kembali lagi karena takut keberadaan monyet memengaruhi kesehatan warga. Menurut Hambali et al. (2012), membangun pagar beton berduri atau pagar kawat akan mengurangi gangguan monyet ekor panjang karena adanya batas dan ancaman seperti duri atau kawat, sehingga monyet enggan menaiki pagar tersebut. Powell (2017) menyatakan bahwa, apabila manusia dan monyet sering melakukan interaksi akan meningkatkan resiko manusia terserang penyakit yang dimiliki oleh monyet tersebut karena monyet merupakan salah satu vektor penyakit yang sering menyerang manusia seperti pneumonia, influenza dan berbagai bakteri patogen.

Warga memberikan saran agar pemerintah mengikutsertakan masyarakat dalam menangani gangguan monyet ekor panjang seperti memindahkan monyet ke kebun binatang ataupun membangun tempat pemeliharaan di Desa Tanjung Mekar. Anju (2015) menyatakan bahwa,pemindahan monyet atau satwa lain yang terjadi konflik dengan manusia ke kebun binatang dapat meningkatkan tingkat keberlangsungan hidup satwa tersebut.

\section{DAFTAR PUSTAKA}

Anju, A., 2015, Crop Raiding and Conflict: Study of Rhesus Macaque-Human Conflict in Shivapuri-Nagarjun National Park, Kathmandu Nepal, Norwegian University Research, Norwegian University of Science and Technology, Department of Biology

BPD, 2017, Profil Desa Tanjung Mekar, Badan Permusyawarahan Desa (BPD)

Dipak, D., dan Sudipta, M., 2015, Man-Monkey Conflict in Khowai District, Tripura, North-East India: A Case Study, Journal of Global Biosciences, Vol 4, No. 8

Ganguli, I., dan Pradipika, V., 2018, Assessment of Human-Macaque Conflict and Possible Mitigation Strategies in and Around Asola-Bhatti Wildlife Sanctuary, Delhi NCR, Environtment \& Ecology, Vol 36, No 3, Hal: 823-827

Hambali, K, Ismail, Zulkifli, S, Munir, B, and Amir, 2012, Human-Macacaque Conflict and
Pest Behaviors of Long-Tailed Macacaque (Macaca fascicularis) in Kuala Selangor Nature Park, Tropical Natural History, Vol 12, No 1, Hal: 189-205

Kumar, P., R, 2014, Human-Monkey Conflict and its Associated Problems at Badarpurghat, Karimganj, Assam (India), Issues and Trends of Wildlife Conservation in Northeast India, ISBN 978-81-924321-7-5

Lane, Michelle, Aida, and Agustin, 2010, Pest, Pestilence, and People: The Long-Tailed Macaque and Its Role in the Cultural Complexities of Bali, Indonesia Primates, Vol 3: 235-248

Mendis dan Ashoka, M, 2016, Human-Monkey (Macaca sinica) Conflict In Sri Lanka, S.L.Vet.J, Vol 63, No 2, Hal: 35-37

Powell, J., 2017, A Global Assessment of MacaqueHuman Interactions, International Conference, Seoul, South Korea

Saraswat, R., Anindya, S., and Sindhu, R., 2015, HumanRhesus Macaque Interactions in Himachal Pradesh, Northern India, EurJ Wild Res, Vol 61: 435-443

Soerianegara, I, 1997, Ekologi Hutan Indonesia, Fakultas Kehutanan IPB, Bogor

Widiyanti, D. R, 2001, Aktivitas Harian Monyet Ekor Panjang (Macaca fascicularis) dan Pengaruhnya Terhadap Pengelolaan Lahan Hutan Rakyat, Fakultas Kehutanan IPB, Bogor. 